\title{
Revista de Artes Marciales Asiáticas
}

Volumen 11(2s), 98-99 2016

DOI: 10.18002/rama.v11i2s.4191

http://revpubli.unileon.es/ojs/index.php/artesmarciales

\section{A posteriori \& a priori knowledge in Taekwondo}

\author{
John A. JOHNSON* \\ Humanitas College, Kyung Hee University - Yongin (South Korea)
}

5th IMACSSS World Scientific Congress Abstracts, Rio Maior (Portugal), October 6-8

Section: Psychological, pedagogic and didactics in MA\&CS

Type: Poster communication

\section{Introduction}

Immanuel Kant bifurcated knowledge into two classes: a priori, or knowledge that is learned through reason or other means which does not require the use of the five senses, and a posteriori, or knowledge that is learned empirically or through experimentation. Epistemology, the branch of philosophy which examines knowledge, has since debated the distinctions of these two types of knowledge (Horrigan, 2007). Also, promulgators of Taekwondo (TKD) have asserted that studying that Korean martial art develops practitioners physically, mentally, and spiritually (Choi, 1985; Rhee, 2012; Adrogué, 2012). Yet, TKD knowledge has not yet been elucidated as either a priori or $a$ posteriori. Thus, this research determines if TKD contains either a priori or a posteriori knowledge. For this paper, TKD as a martial art (i.e., a system of self-cultivation) was examined, because all other forms of TKD stem historically from this purpose (Adrogué, 2003; Moenig, et al., 2014). Research has determined that TKD can be defined according to how it is practiced (Wasik, 2014; Johnson \& Ha, 2015; Dziwenka \& Johnson, 2015). Recent unbiased accounts of TKD history indicate a strong roots in Japanese martial arts (Adrogué, 2003; Gillis, 2011; Moenig, 2011; Moenig, et al., 2014). Japanese martial arts have been researched for decades and offer a plethora of insights into their Korean counterparts. For instance, the pedagogy of Judo, which is arguably the first martial art with the goal of self-cultivation and where modern -do suffixed martial arts stem from, is wellresearched (Kano, 1989; Kodokan, 2009). Like Judo (Kano, 1989), TKD has three stages of learning: musul (martial technique), muyae (martial artistry), and mudo (martial 'way') (Johnson, 2016).

\section{Methodology}

Kant's a priori or a posteriori knowledge were first defined. Next, TKD's three stages of learning, called musul, muyae, and mudo, were delineated according to the most recent published literature on TKD pedagogy. TKD knowledge, or knowledge acquired during or through the practice of TKD (Mayen, et al., 2015), has been categorized as musul, muyae, and mudo epistemologically (Johnson, 2016), which contradicts the more ontological-inclined understanding of the terms (Yang, 1999). As competing interpretations of these concepts exist, the educational perception was applied to the current research as that theory corresponds to skill (i.e., kinesthetic knowledge) acquisition models. Research has shown that TKD knowledge corresponds to the various levels found in skill acquisition (Johnson, 2016), so it was hypothesized that TKD could be categorized as either a priori or a posteriori based upon the knowledge TKD students acquire at each stage. To elucidate whether Taekwondo knowledge is apriori or aposteriori in nature, what is learned at the musul, muyae, and mudo was determined and then categorized as either a priori or a posteriori knowledge.

\section{Results}

TKD has practical (i.e., kinesthetic) knowledge whilst providing a means of self-cultivation (i.e., non-kinesthetic knowledge). The practical knowledge found in TKD was understood as a posteriori, because it must be tested for effectiveness either in battle or in competition. The non-kinesthetic knowledge was determined to be a priori knowledge, because it is acquired through practitioners'

${ }^{*}$ Email: mudoknowledge@gmail.com 
personal rationalizations to apply TKD knowledge to their daily lives (i.e., reason). TKD thus possesses two types of knowledge: a posteriori knowledge, which is found at the musul and muyae stages of learning, and a priori, which is identified at the mudo level. Uniquely, TKD's pedagogical process illustrates that it is possible to have both a priori and a posteriori within one discipline.

\section{Discussion and conclusion}

This paper proposes that a priori and a posteriori knowledge are existent within TKD knowledge in particular and, in a wider view, all martial arts with a -do suffix. It was found that a Kantian approach to TKD pedagogy can provide a guided course of study for all TKD students regardless of their experience levels. This pedagogical paradigm of TKD and can withstand academic scrutiny better than previous philosophical and pedagogical theories for four reasons: 1) it avoids the problems incurred by the ontological-based TKD philosophies and pedagogies, namely the innate conflict they create when introduced to students with existing religious beliefs and their inability to improve students' understanding of TKD itself; 2 ) it avoids inaccurate and overtly nationalistic TKD histories, which other philosophies use to substantiate their conclusions; 3 ) it is easily incorporated into all TKD programs regardless of their final educational aim (e.g., self-defense, self-cultivation, sport, etc.), and 4) it approaches TKD philosophy from examining what TKD is rather than what it could be.

\section{References}

Adrogué M. E. (2003). Ancient military manuals and their relation to modern Korean martial arts. Journal of Asian Martial Arts, 12(4), 8-33.

Adrogué, M. E. (2012). Classical Taekwondo. In M. A. DeMarco (Ed.), Asian Martial arts: Constructive Thoughts and Practical Applications (pp. 40-43). Santa Fe, NM: Via Media Publishing.

Choi, H. H. (1985). Encyclopedia of Taekwon-Do (Vol. 1). International Taekwon-Do Federation.

Dziwenka, R., \& Johnson, J. A. (2015). Philosophical perspectives of practice: Traditional martial arts Taekwondo vs. modern sports Taekwondo. Journal of the International Association for Taekwondo Research, 2(2), 1-8.

Gillis, A. (2011). A Killing Art: The Untold History of Tae Kwon Do. Toronto, Canada: ECW Press.

Horrigan, P. G. (2007). Epistemology: An Introduction to the Philosophy of Knowledge. Lincoln, NE: iUniverse.

Johnson J. A. (2016). The Pedagogical Process of Taekwondo. Proceedings from the $10^{\text {th }}$ International Conference on Kinanthropology. Brno, Czech Republic: Masaryk University.

Johnson, J. A., \& Ha, P. (2015). Elucidating pedagogical objectives for combat systems, martial arts, and combat sports. Ido Movement for Culture. Journal of Martial Arts Anthropology, 15(4), 65-74.

Kano, J. (1989). The contribution of Jiudo to education. In R. F. Nelson (Ed.), The Overlook Martial Arts Reader: Classic Writings on Philosophy and Technique (pp. 199-209). Woodstock, NY: Overlook Press.

Kodokan. (2009). Jigoro Kano and the Kodokan: An Innovative Response to Modernisation. Tokyo, Japan: Shūsansha.

Mayen, J., Johnson, J. A., \& Bosch, R. M. (2015). Taekwondo as one's life philosophy. Journal of the International Association for Taekwondo Research, 2(1), 24-29.

Moenig, U. (2011). The evolution of kicking techniques in Taekwondo. Journal of Asian Martial Arts, 20(1), 8-31.

Moenig, U., Cho, S., \& Kwak, T. Y. (2014). Evidence of Taekwondo's roots in Karate: An analysis of the technical content of early Taekwondo literature. Korea Journal, 54(2), 150-178.

Rhee, K. H. (2012). This Is Taekwon-Do. United Kingdom: Media Insight.

Russell, B. (2007). A priori justification and knowledge. In E. N. Zalta (Ed.), Stanford Encyclopedia of Philosophy. Retrieved from http://plato.stanford.edu/archives/sum2013/entries/apriori/

Wasik J. (2014). Three areas of Taekwon-do identification and practice. Ido Movement for Culture. Journal of Martial Arts Anthropology, 14(3), 22-26.

Yang J. B. (1999). A new framework for the reconceptualization of mu-sul, mu-ye, mu-do. Journal of Korean Alliance of Martial Arts, 1(1), 27-37. (In Korean).

Key words: Immanuel Kant; do; musul; muyae; mudo; Taekwondo pedagogy; combat sports. 